\title{
Surface damage from perpendicular and oblique bullet impacts in stone
}

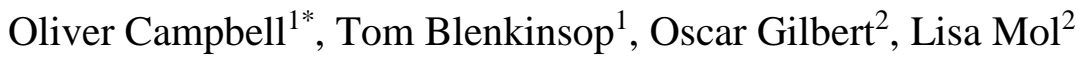 \\ ${ }^{I}$ School of Earth and Ocean Sciences, Cardiff University, Cardiff, UK \\ ${ }^{2}$ Department of Geography and Environmental Management, University of the West of England, Bristol, UK
}

Keywords: Photogrammetry, bullet impact, crater morphology, oblique impact, asymmetry, heritage

\section{This is a non-peer reviewed preprint submitted to Earth ArXiv. It has been submitted to Royal Society Open Science for peer review.}

\section{Summary}

Controlled experiments were conducted to investigate the surface damage caused by perpendicular and oblique impacts of bullets into sandstone and limestone targets. Individual bullets fired in conditions simulating modern rifles at typical combat distances excavated craters with diameters from 22 to $74 \mathrm{~mm}$ and depths from 4 to $24 \mathrm{~mm}$. Limestone target craters were up to twice as large and deep as those in sandstone. These craters have a complex shape consisting of a central excavation surrounded by a shallow dish, compared to the simple bowl shape of most sandstone impacts. Radial fractures extending to the edge of the target block were common in limestone targets. Impacts at an angle of $45^{\circ}$ to the surface in both rock types result in asymmetric craters. Two common types of ammunition were compared: the steel-tipped NATO projectile generally produced larger and deeper craters than the projectile that is commonly fired from AK-47 rifles, despite having approximately half the mass of the latter. These results characterise the sort of damage that can be expected at many sites of cultural significance involved in contemporary conflict zones, and have important implications for their conservation.

\section{Introduction}

As contemporary armed conflicts shift towards more urbanised areas, the risk of damage to non-military targets, such as homes, shops, and places of worship, increases. The most dramatic manifestations of armed conflict are destruction from explosives, rockets, and heavy artillery, particularly to sites of cultural significance e.g. the ideologically driven destruction of Mosul and Palmyra by Islamic State (IS)/Da'esh [1]. In contrast, bullet impacts and shrapnel damage are less obvious, and commonly overlooked in damage assessment. There are few studies on the quantitative effects of this widespread form of damage, especially in natural stone that typifies culturally important sites, but initial results suggest these impacts increase deterioration of sites in the long term [2-4].

Bullet impacts cause compaction and grain fracture directly below the impact, increase surface permeability, and reduce surface hardness around the impact [4,5]. Campbell et al., [6] showed that surface damage such as craters and fractures is linked to 4-7 times more damage by surface area in the sub-surface than the crater itself. Microstructural analysis from below the impact showed open aperture fracture networks decreasing in intensity with distance from the crater floor [6]. These factors aid the ingress of weathering agents such as moisture and salts into the stone, enlarging the region at risk of deterioration [7]. The expansive crystallisation of salt from solution widens fracture apertures and pushes grains apart, reducing overall stone strength [8]. Larger fracture apertures and greater porosity also enhance the flow of moisture through capillary rise and surface evaporation. This moisture can lead to dissolution of constituent minerals and cement, further exacerbating stone deterioration through a negative feedback cycle of increasing porosity and decreasing strength [9-11]. It is therefore important for any conservation efforts that the spatial distribution and morphology of surface damage is understood, in order to appreciate the full likely scope of damage, including the sub-surface effects. 
Experiments have shown that impact variables such as projectile mass, velocity, and angle of impact affect the distribution and morphology of damage. Impact experiments and simulations with projectile trajectories perpendicular to the target face can be constrained with well-defined power-law relationships between impact variables, which are useful in investigating the effects of different variables on resultant damage [12-14]. Perpendicular impacts are generally modelled by spherical stress waves, leading to a symmetric distribution of damage. However, few previous studies have considered the heterogeneity of natural target materials, such as stone [15]. Perpendicular impacts also do not represent a 'natural' conflict zone comprehensively, where the angle of impact is likely to be oblique $\left(<90^{\circ}\right)$.

The angle of impact affects the morphology of impact damage. Crater shape in hypervelocity impact experiments into loose quartz sand remains circular until impact angles fall below $30^{\circ}$, and in granite targets only elongates at impact angles $<15^{\circ}$ [16]. However, numerical modelling by Pierazzo et al., [17] indicates that the location of peak pressures in the target move down-range and closer to the target surface in oblique impacts, even at incident angles as steep as $60^{\circ}$. This suggests that any degree of obliquity in projectile impact could

(a)

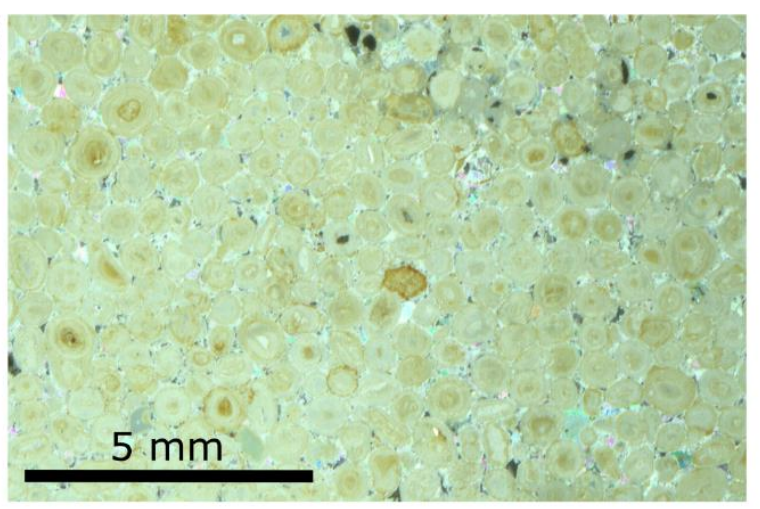

(c)

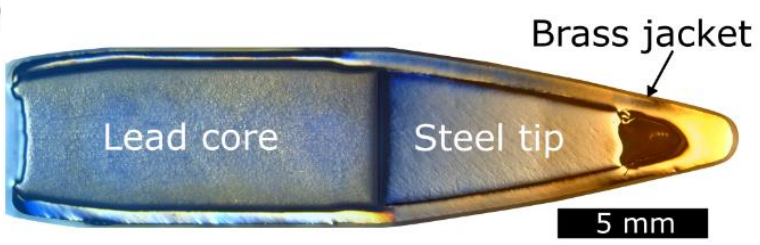

(e)

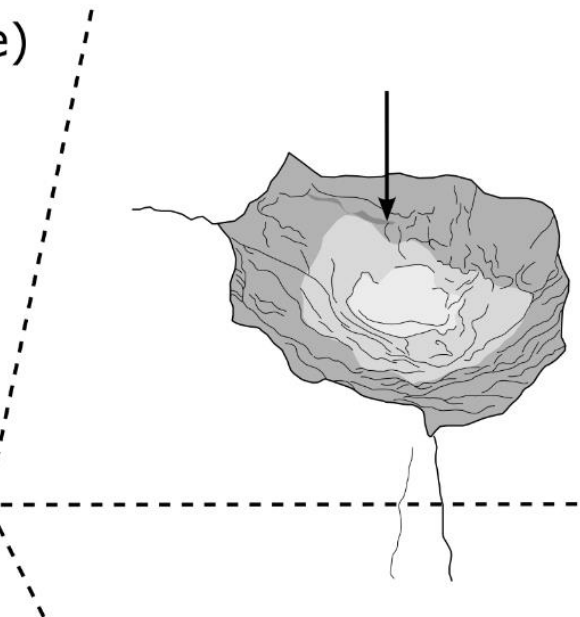

(b)

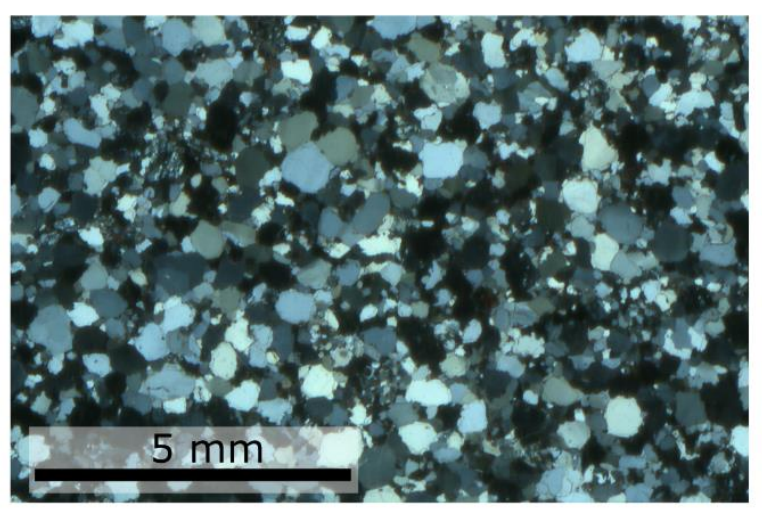

(d)

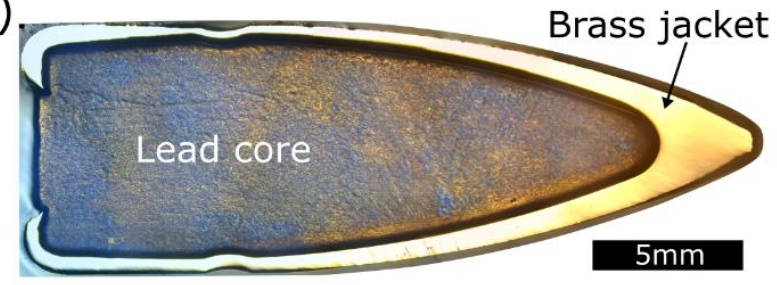

(f)

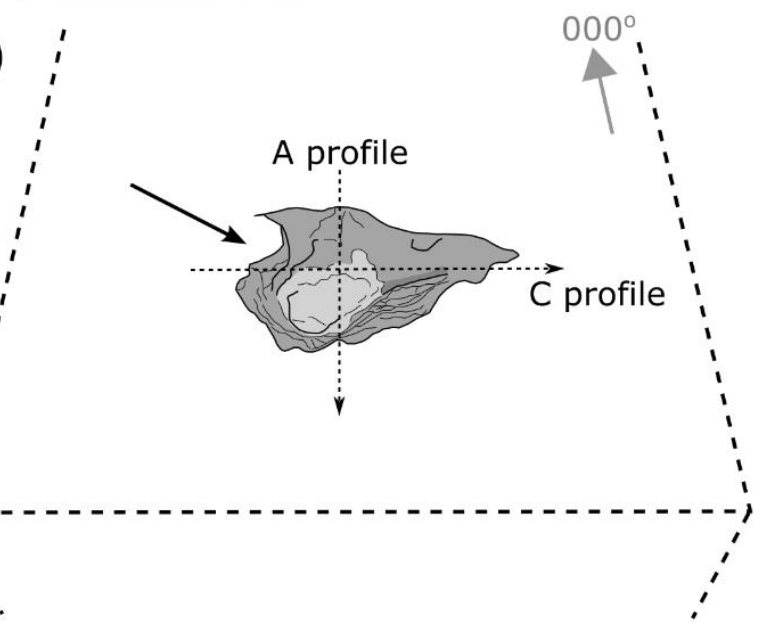

Figure 1: (a) Thin section photomicrograph of undamaged Cotswold Hill Cream Limestone under cross polarised light. Spherical ooids can be seen tightly packed, with most pore space infilled with sparry calcite crystals. (b) Thin section photomicrograph of undamaged Stoneraise Red Sandstone under cross polarised light. Grains are predominantly quartz, with many exhibiting orange-brown Fe-oxidation rims that have been subsequently overgrown. (c) Reflected light micrograph of a NATO projectile in cross section, comprising of three parts: a surrounding brass jacket, a steel tip in the nose, and a lead core in the body of the projectile. This differs from the $7.62 \times 29 \mathrm{~mm}$ projectile (d) which has only a brass jacket and fully lead core. (d) Reflected light photo micrograph of $7.62 \times 39 \mathrm{~mm}$ projectile in cross section (from Campbell et al., [6]). (e-f) Schematic diagrams showing the angle of impact for perpendicular $\left(90^{\circ}\right)$ and oblique $\left(45^{\circ}\right)$ impacts respectively with relation to the target face. Dashed arrows show the orientation of the A and C profiles measured for each sample. 
cause an asymmetric distribution of stress and resultant damage, but there is an uncertainty about this effect. Distinguishing oblique from perpendicular impacts on damaged heritage is important for identifying regions that may be more prone to future deterioration.

The aim of this study is to provide quantitative assessment of damage caused by modern rifle bullets in scenarios typical of modern conflict, particularly in the context of sites of cultural heritage. Due to protections surrounding heritage, methods of study need to minimise additional damage or deterioration. Digital photogrammetry provides a means of capturing data from field sites for further analysis, and is a completely non-destructive approach. Such digital means have been useful in recording heritage and mapping decay $[18,19]$. This study uses digital 3D models of experimental bullet damage into targets consisting of two different types of natural stone, with two different but commonly used types of ammunition. The study compares crater morphology from perpendicular and $45^{\circ}$ impacts, and suggests several criteria for differentiating them.

\section{Materials and Methods}

Target materials and projectile properties

Freshly quarried cubes $(15 \times 15 \times 15 \mathrm{~cm})$ of Stoneraise Red Sandstone (SRS)(18No.) and Cotswold Hill Cream Limestone (CHCL)(12No.) were selected as target stones because of their analogous lithology and mechanical properties to heritage stones in the Middle East, such as the Mokattam Limestone of Egypt, and the Umm Ishrin sandstones of Petra, Jordan [20-22]. The Cotswold Hill Cream Limestone is an oolitic grainstone from the Middle Jurassic Inferior Oolite (quarried near Ford, UK). The average grain size is $0.5 \mathrm{~mm}$ and the porosity $\sim 20$ $\%$. (Figure 1a).The Stoneraise Red Sandstone is a fine-medium $(0.125-0.5 \mathrm{~mm})$, quartz rich sandstone from the Permian New Red Sandstones (quarried near Penrith, U.K.) (Figure 1b). It has a porosity of $\sim 11 \%$ and is generally massive, though some blocks exhibit visible beds of coarser grains ( 1 mm).

Controlled firearm experiments were carried out at Cranfield Ordnance Test and Evaluation Centre (Gore Cross, UK) to simulate conflict damage to stone. Two different types of ammunition used in contemporary and past conflicts were fired at incident angles of $90^{\circ}$ and $45^{\circ}$ to the target face. Firstly, $5.56 \times 45 \mathrm{~mm}$ NATO (abbreviated as NATO) is a standardised cartridge used in the British SA80 assault rifle, the American M16 family of assault rifles, as well as many other military issue firearms around the world. The second ammunition type is a $7.62 \times 39 \mathrm{~mm}$ cartridge (abbreviated as AK-47), commonly fired from AK-variant rifles, such as the widely known AK-47. Both ammunition types are a spitzer ogive nosed projectile with a brass jacket and lead core. The NATO projectile also has a steel tip within the brass jacket (Figures 1c and 1d). The AK-47 projectile has a mass of 7.95 grams (123 grains) and the NATO projectile has a mass of 4.04 grams (63 grains). Both cartridges were remotely fired from mounted proof barrels $14 \mathrm{~m}$ from the target. Propellant loads for each cartridge were adjusted to reduce velocity and simulate impacts at distances of $200 \mathrm{~m}$. Average engagement distances in urban firefights during the Iraq War ranged from $26 \mathrm{~m}$ to over $126 \mathrm{~m}$ between combatants, and most soldiers are trained for engagement distances of $0-600 \mathrm{~m}$, so $200 \mathrm{~m}$ represents a reasonable distance for simulating impacts in both urban and open scenarios [23,24]. Additional adjustments were made to simulate a range of $400 \mathrm{~m}$, as well as one shot conducted at standard propellant load (impact at muzzle velocity). Concrete blocks were placed on all faces, except the target face, for confinement. Target blocks with bedding were oriented so that foliations were parallel to the target face.

A 14-megapixel Fujifilm FinePix S3400 digital camera was used to photograph damaged samples through a $360^{\circ}$ rotation at three overlapping camera positions. Samples were then overturned and the process was repeated. Additional images were taken of the impact crater to ensure adequate capture of morphology. Meshroom (version 2020.1.1), a free and open-source structure from motion (SfM) pipeline developed by AliceVision ${ }^{\circledR}$, was used to process the $\sim 300-400$ images for each block into a 3D mesh $[25,26]$. In CloudCompare (version 2.11.3, 2020), impact damage was isolated from the full block mesh to reduce processing times, then scaled and oriented with the target surface horizontal and an azimuth direction of $000^{\circ}$ directed towards the top edge of the block (Figure 1f).

Depth maps were generated in CloudCompare and further processed in Python. Eighteen cross section profiles, centred on the deepest point of the crater, were measured at $10^{\circ}$ increments. An average profile was calculated for regions with data points from all 18 profiles. Four analogue cross section profiles, centred on the visually determined deepest point, were measured at $45^{\circ}$ increments by placing a $150 \mathrm{~mm}$ Barton profile comb across impact craters. The comb profile was then photographed and digitised in QGIS (version 3.16.0), to be compared to digital profiles along the same orientation to ground truth the models. Once aligned, the Root Mean Square (RMS) difference between the comb profile $\left(P_{c}\right)$ and digital profile $\left(P_{d}\right)$ was calculated using Equation 1: 


$$
\text { RMS difference }=\sqrt{\frac{\sum_{i=1}^{n}\left(P_{c i}-P_{d i}\right)^{2}}{n}}
$$

The RMS difference for each sample was normalised $\left(R M S_{N}\right)$ to the maximum profile depth, as measured by the comb profile, to enable comparison between samples:

$$
R M S_{N}=\frac{R M S \text { difference }}{\text { Max depth }}
$$

Impact craters were outlined in QGIS from plan view photographs. The edge of the crater was defined visually as the transition point from a depression to undamaged target face. These outlines were analysed in ImageJ (version 1.53h) to calculate the crater area, aspect ratio, and geometric centre. An area (A) equivalent diameter $\left(D_{e q}\right)$ of the crater area was calculated using:

$$
D_{e q}=2 \sqrt{\frac{A}{\pi}}
$$

\section{Results}

All samples experienced the loss of material and the formation of an impact crater which contained fine grained, powdery material and a pale discolouration in the central region. Crater size and morphology differs between lithology, angle of impact, and projectile type.

$90^{\circ}$ impact trajectory

Sandstone targets shot with AK-47 projectiles have shallow, bowl shaped craters with an average depth of $4.09 \mathrm{~mm}$ and an average diameter of $31.19 \mathrm{~mm}$ (Table 1). An average aspect ratio of 1.10 supports visual observations of a roughly circular shape. There are few visible surface fractures surrounding the craters, but if present, they are short and appear closed. Within and around some craters there is a dark grey discolouration

\begin{tabular}{|c|c|c|c|c|c|c|}
\hline $\begin{array}{l}\text { Ammunition } \\
\text { / Projectile }\end{array}$ & Target & $\begin{array}{l}\text { Angle of } \\
\text { Impact }\left({ }^{\circ}\right)\end{array}$ & $\begin{array}{c}d \\
(\mathbf{m m})\end{array}$ & $\begin{array}{c}D_{e q} \\
(\mathbf{m m})\end{array}$ & $\begin{array}{l}\text { Aspect } \\
\text { Ratio }\end{array}$ & Fractures \\
\hline \multirow{4}{*}{ NATO } & \multirow{2}{*}{ Limestone } & 90 & 15.65 & 63.55 & 1.18 & $\begin{array}{c}\text { Radial, open aperture fractures to the } \\
\text { edge of the block }\end{array}$ \\
\hline & & 45 & 10.28 & 46.32 & 1.19 & $\begin{array}{l}\text { Open aperture fractures mostly } \\
\text { extend to edge of block }\end{array}$ \\
\hline & \multirow{2}{*}{ Sandstone } & 90 & 13.29 & 50.82 & 1.17 & $\begin{array}{l}\text { Radial fractures with open apertures } \\
\text { in some samples }\end{array}$ \\
\hline & & 45 & 6.48 & 35.53 & 1.45 & $\begin{array}{l}\text { Few very short fractures with closed } \\
\text { apertures }\end{array}$ \\
\hline \multirow{4}{*}{ AK-47 } & \multirow[t]{2}{*}{ Limestone } & 90 & 23.95 & 73.97 & 1.14 & $\begin{array}{l}\text { Open radial fractures to the edge of } \\
\text { the block. Spall fragments bordered } \\
\text { by narrow fractures concentric with } \\
\text { crater edge }\end{array}$ \\
\hline & & 45 & 8.99 & 41.22 & 1.24 & $\begin{array}{l}\text { One sample has open aperture } \\
\text { fractures to the edge of the block. }\end{array}$ \\
\hline & \multirow[b]{2}{*}{ Sandstone } & 90 & 4.09 & 31.19 & 1.10 & Short fractures with closed apertures \\
\hline & & 45 & 3.52 & 21.59 & 1.16 & $\begin{array}{l}\text { Narrow aperture fractures to the } \\
\text { edge of the block in some samples. }\end{array}$ \\
\hline
\end{tabular}
from the lead within the projectile. The cross section profiles through impacts have a rotational symmetry around the centre of the crater (Figure 2).

Table 1: Summary of the average crater parameters for each firing condition and description of visible surface fractures on the target. $d=$ max depth, $D_{\text {eq }}=$ area equivalent diameter.

Limestone targets shot with the same projectile type have deeper $(23.95 \mathrm{~mm})$ and wider $(73.97 \mathrm{~mm}) \mathrm{impact}$ craters than sandstone targets. The crater morphology is composed of two regions, a steep sided central region, and surrounding that a shallower dipping spall region separated by a change in slope (arrows in Figure 3c). Some impacts have prominent radial fractures emanating from the crater edges, in some instances with apertures several $\mathrm{mm}$ wide and extending to adjacent faces. Other samples only have one or two radial fractures with narrow apertures $(\sim 1 \mathrm{~mm})$, which can also extend to the edge of target face. Some samples have incipient 
spall fragments that are raised above the target face. They are bordered by very narrow aperture fractures that are roughly concentric to the crater edge.

Impacts into sandstone targets with NATO projectiles produced craters on average 3.25 times deeper (13.29 $\mathrm{mm}$ vs $4.09 \mathrm{~mm}$ ) and 1.6 times wider $(50.82 \mathrm{~mm}$ vs $31.19 \mathrm{~mm})$ than AK- 47 projectile impacts. Craters have a slightly higher aspect ratio of 1.17 , and a crater outline that tends towards a square shape. Some craters have radial fractures with visible open apertures away from the crater. The steel tip from the projectile remains embedded in the crater floor. Crater profile morphology is more complex than the simple bowl craters observed in AK-47 projectile impacts. Profiles have a central region with steep sides and shallow dipping outer spall region, similar to impacts of AK-47 projectiles into limestone targets.

Figure 2: Summary of 18 cross sections for each sample. Profiles $\pm 45^{\circ}$ to $000^{\circ}$ are coloured green, while profiles $\pm 45^{\circ}$ to $090^{\circ}$ are dashed grey. Note the asymmetry imposed by the $45^{\circ}$ impact in sample SRS_22 (f). Profiles with similar azimuth to projectile trajectory (grey dash) have a wider diameter and shallower slopes, whilst profiles orthogonal to this (green) have steeper slopes and a narrow diameter. Other angled impacts show steeper dipping up-range sides and shallower dipping down-range ones (e.g. sample CHCL_25 (d) and CHCL_30 (h). Incipient spall fragments can be identified as areas raised above $0 \mathrm{~mm}$ depth on crater edges (e.g. between -20 and $-10 \mathrm{~mm}$ on sample CHCL_25 (d) and $+15 \mathrm{~mm}$ on sample CHCL_30 (h). Direction of projectile is left to right for $45^{\circ}$ impacts. Profiles and depth maps of all samples can be found in supplementary data. 
(a)

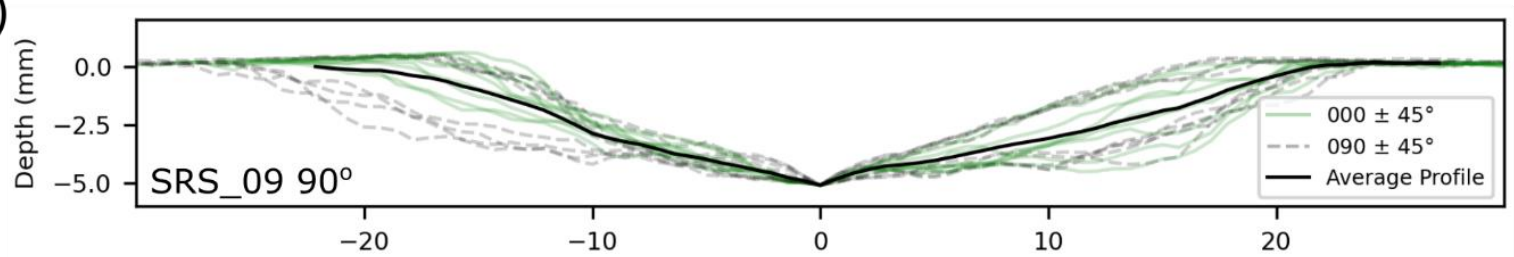

(b)

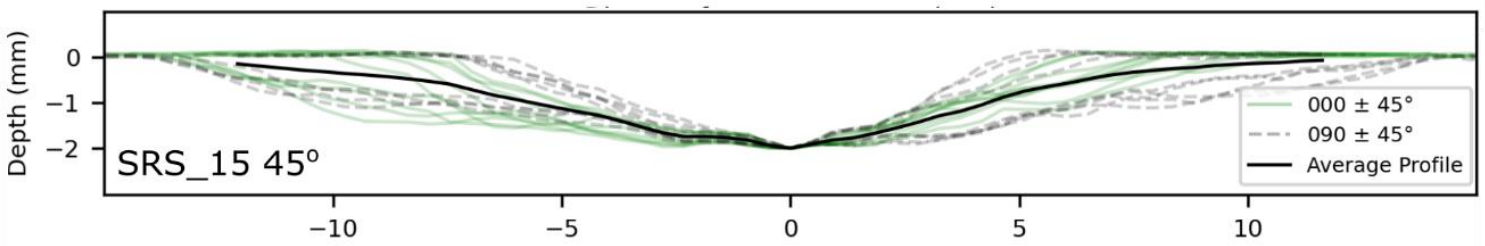

(c)

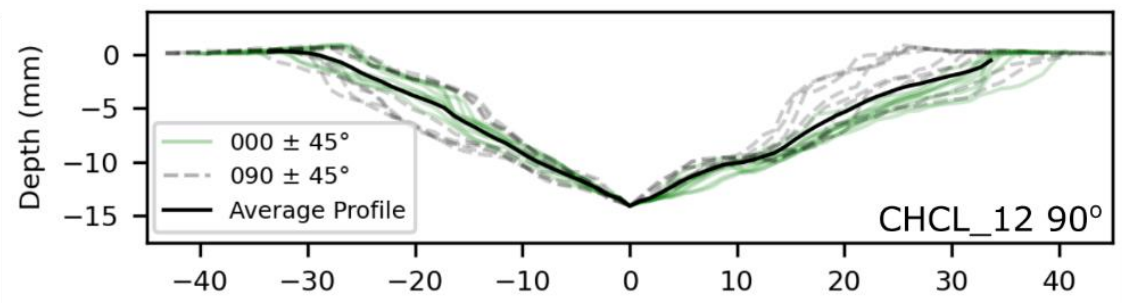

(d)

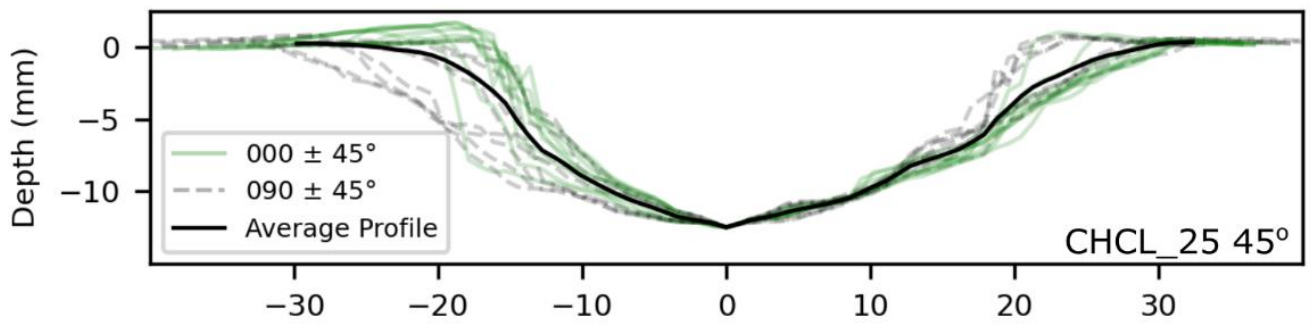

(e)

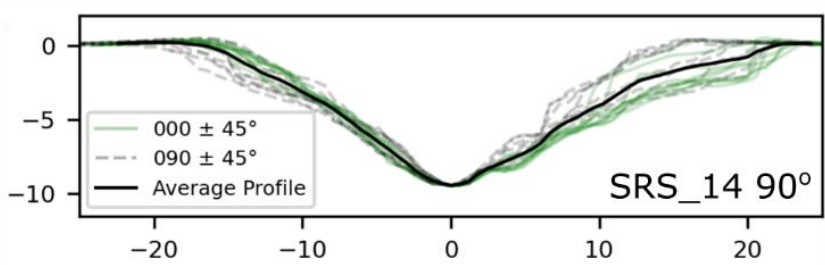

(f)

(g)

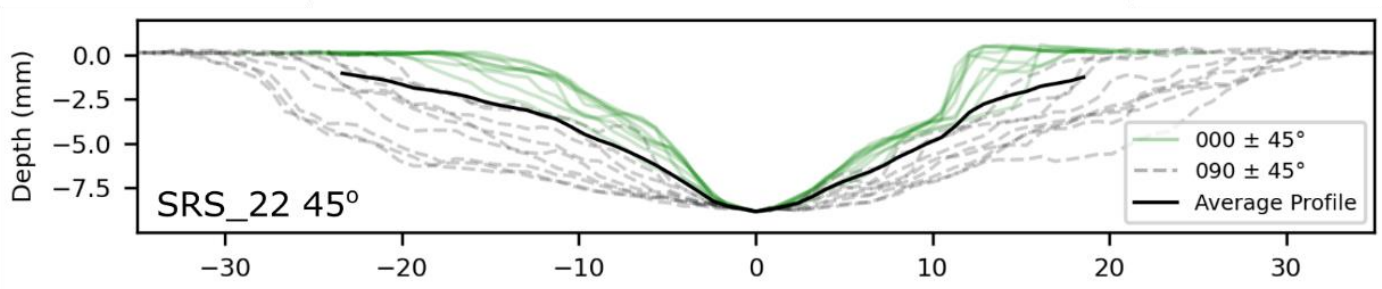

(h)
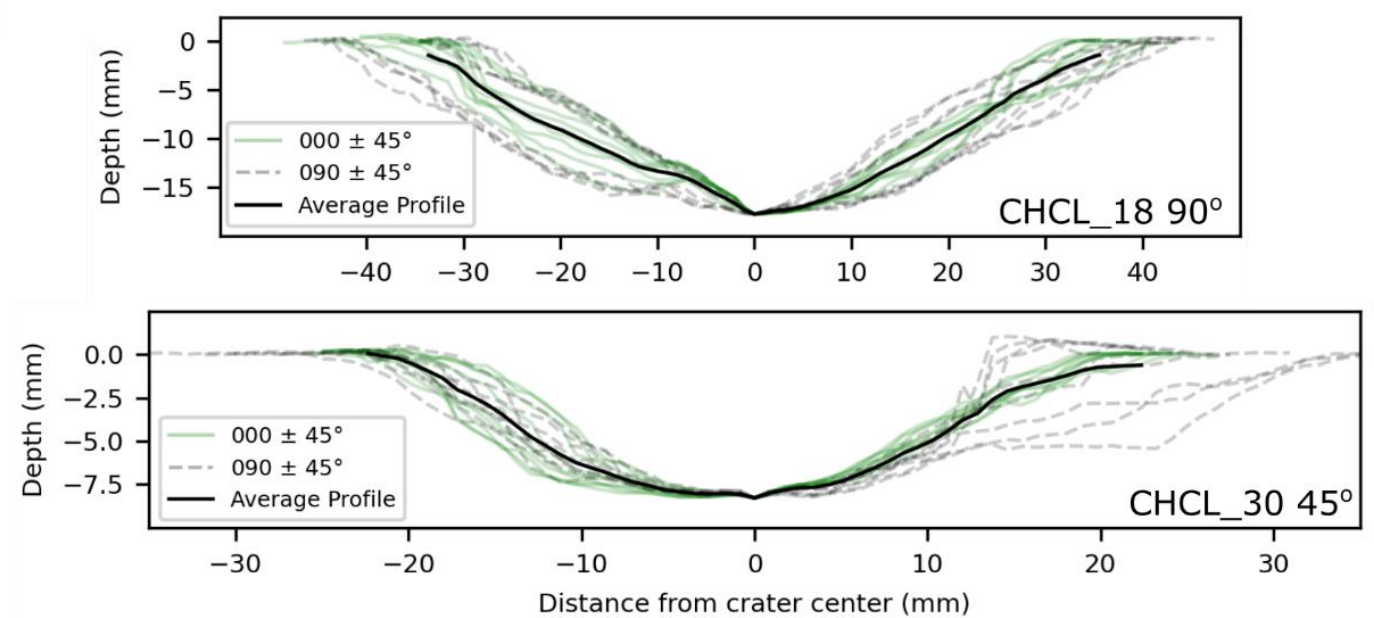

Limestone targets shot with NATO projectiles have, on average, shallower $(15.65 \mathrm{~mm})$ and narrower $(63.55$ $\mathrm{mm}$ ) craters than those shot with AK-47 projectiles. All craters have open aperture radial fractures that extend to the edge of the block, though apertures are not as wide as seen in AK-47 projectile impacts. There are metal smears and grey lead deposits at the base of the craters, with the steel tip either embedded or absent, leaving a small central depression at the base of the crater. This depression is reflected in the cross sectional profiles as a 
vertical sided pit at the middle of the profile (see supplementary data). Crater morphology is similar to other impacts in that it has a steep sided central region surrounded by a shallower dipping spall zone.

$45^{\circ}$ impact trajectory

Sandstones targets impacted with AK-47 projectiles at $45^{\circ}$ have extremely shallow $(3.52 \mathrm{~mm})$ craters with an average diameter of $21.59 \mathrm{~mm}$. Crater shape is still roughly circular with an aspect ratio of 1.16, though this is slightly larger than perpendicular impacts at the same conditions. Cross sections along the same axis as the projectile trajectory (C Profiles) show an asymmetry in morphology. They have a shorter, steeper wall on the up-range (towards $270^{\circ}$ ) side and a longer shallower wall on the down-trajectory side (towards $090^{\circ}$ ). The morphology of the orthogonal A profile is more symmetrical. Dark-grey lead residue is present on down-range regions of the crater edge and adjacent to the crater on the target face.

Limestone targets impacted by AK-47 projectiles at $45^{\circ}$ have the highest aspect ratio (1.24) of all samples across both rock types impacted using this projectile. The impact craters are on average shallower $(9.0 \mathrm{~mm})$ and

\begin{tabular}{|c|c|c|}
\hline $\begin{array}{c}\text { Ammunition/ } \\
\text { Projectile }\end{array}$ & Target & $\begin{array}{c}\text { Average } \\
\text { RMS } \\
\text { difference }\end{array}$ \\
\hline \multirow{4}{*}{ NATO } & \multirow{2}{*}{ Limestone } & $6.0 \%$ \\
\hline & & $10.1 \%$ \\
\hline & \multirow{2}{*}{ Sandstone } & $9.2 \%$ \\
\hline & & $9.7 \%$ \\
\hline \multirow{4}{*}{ AK-47 } & \multirow{2}{*}{ Limestone } & $13.1 \%$ \\
\hline & & $15.7 \%$ \\
\hline & \multirow{2}{*}{ Sandstone } & $18.0 \%$ \\
\hline & & $12.5 \%$ \\
\hline
\end{tabular}
smaller in diameter $(41.22 \mathrm{~mm})$ than perpendicular impacts into the same target material. The two samples shot under these conditions, are quite different. One sample shot at $45^{\circ}$ (CHCL_25) has incipient spall fragments at the crater edge, and open aperture fractures that extend from the crater to the edge of the block. This differs from another sample (CHCL_28) shot under the same conditions, which has no radial fractures around the crater and a greater difference between analogue and digital profiles (Table 2).

Table 2: Average root men square difference (RMS) between profiles obtained via the Barton comb method and from digital photogrammetry models.

Figure 3: Depth maps (left) of impact craters caused by AK-47 projectiles into blocks of Stoneraise Red Sandstone (SRS) $(a-b)$ and Cotswold Hill Cream Limestone (CHCL) $(c-d)$. Black line is the crater outline, the white cross $(+)$ is the deepest point of the crater, and the white circle marks the geometric centre. Black arrows indicate the change of slope between central depression and outer spall zone. Direction of projectile is left to right for $45^{\circ}$ impacts. Adjacent to each depth map (right) is a comparison of digital (black line) and analogue comb (red) profiles taken at $45^{\circ}$ intervals starting at $000^{\circ}$ (labelled $A-D$ ). The dashed grey line shows the original undamaged target face. Root mean square difference (RMS) values are in mm. Profiles and depth maps of all samples can be found in supplementary data. 
(a)
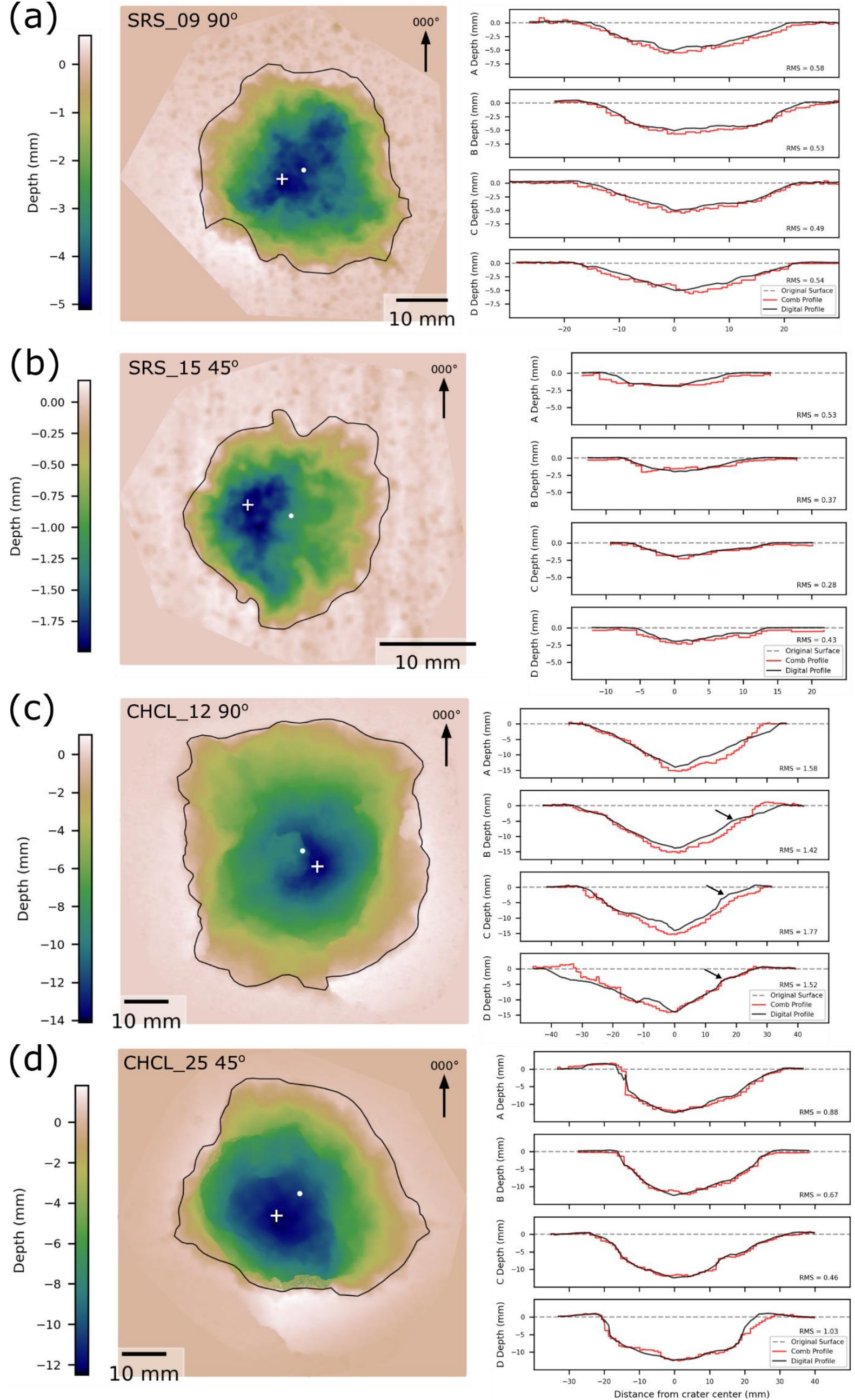
(a)

(b)
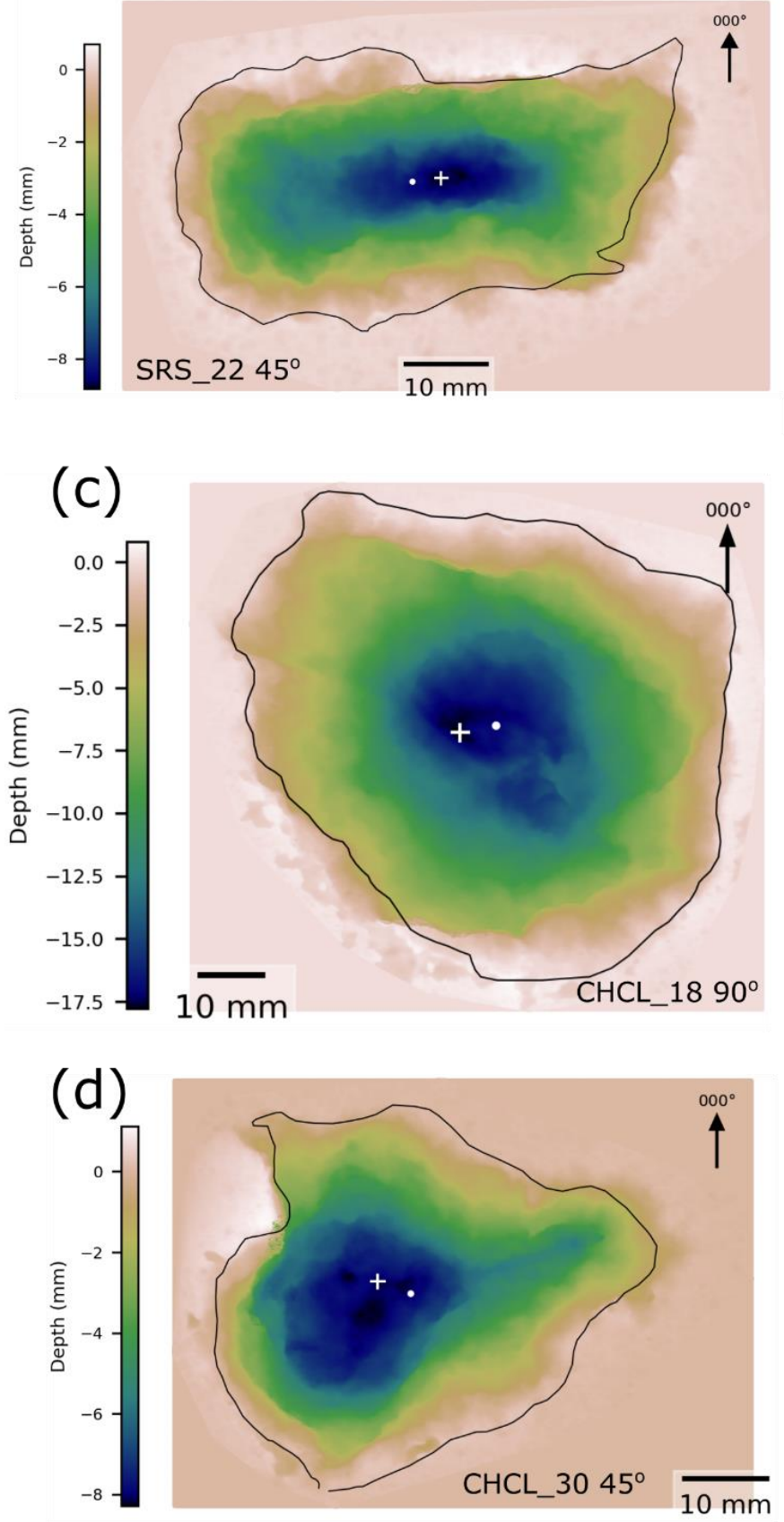

SRS $\_1490^{\circ}$

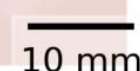


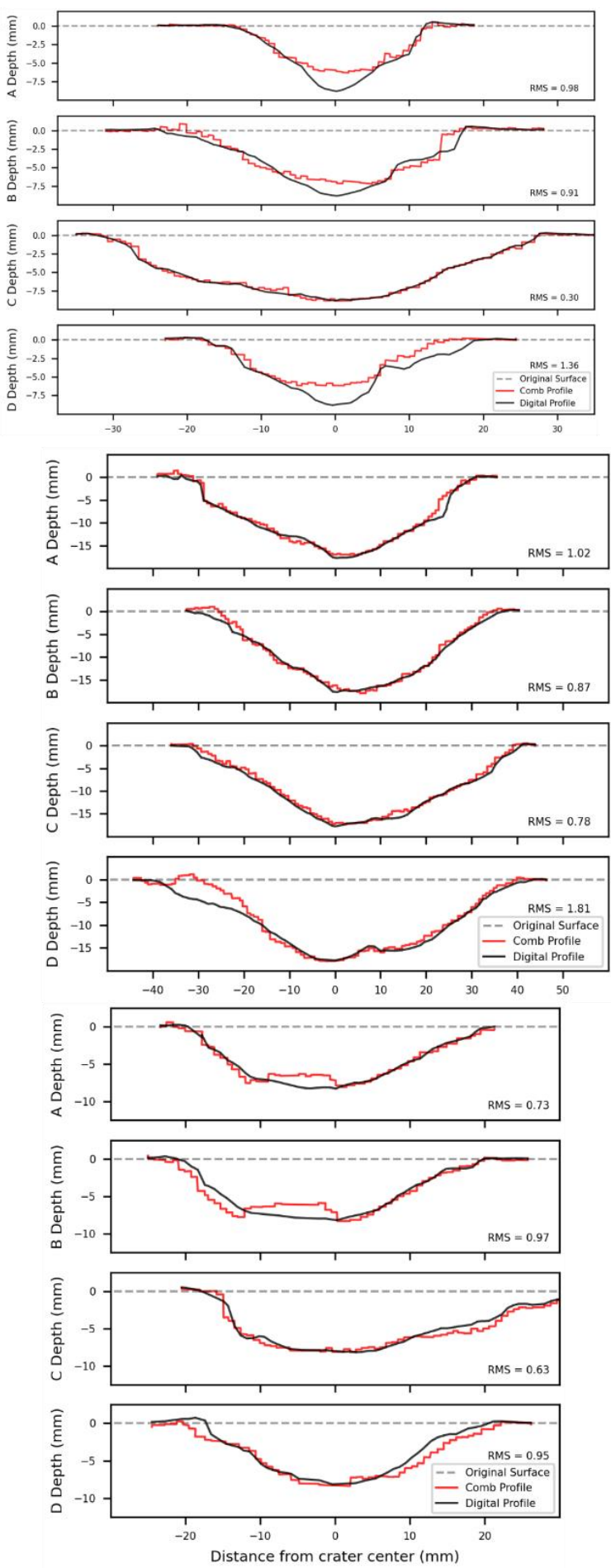
Figure 4: Depth maps (left) of impact craters caused by NATO projectiles into Stoneraise Red Sandstone (a-b) and Cotswold Hill Cream Limestone (c-d). Black line is the crater outline, the white cross (+) is the deepest point of the crater, and the white circle marks the geometric centre. Direction of projectile is left to right for $45^{\circ}$ impacts. Adjacent to each depth map (right) is a comparison of digital (black line) and analogue comb (red) profiles taken at $45^{\circ}$ intervals starting at $000^{\circ}$ (labelled A-D). The dashed grey line shows the original undamaged target face. Root mean square difference (RMS) values are in mm. Profiles and depth maps of all samples can be found in supplementary data.

Oblique impacts of NATO projectiles into sandstone targets resulted in the most elongate craters of any conditions, with an average aspect ratio of 1.45 . Crater depth averages $6.48 \mathrm{~mm}$ and average diameters 35.53 $\mathrm{mm}$. These craters are larger than sandstone targets impacted by AK-47 projectiles at both angles of impact. The long axis of the crater is (sub) parallel to the trajectory of the projectile. The cross section profiles reflect the higher aspect ratio, with profiles $\pm 45^{\circ}$ of the A profile $\left(000^{\circ}\right)$ showing a narrower, steeper sided cross section, while profiles $\pm 45^{\circ}$ of the $\mathrm{C}$ profile are wider with shallower dipping sides (Figure $2 \mathrm{f}$ ).

Much like other angled impacts, NATO projectiles produce shallower $(10.28 \mathrm{~mm})$ and narrower $(46.32 \mathrm{~mm})$ impact craters in limestone targets than perpendicular impacts with the same projectile. Impact craters under these conditions generally fall into 2 groups based on crater morphology. The first group has many, open aperture fractures radiating from the crater to the edge of the target block. Fracture orientations are predominantly between $000^{\circ}$ and $180^{\circ}$ i.e. in the down-range half of the block. This group also has multiple incipient spall fragments bordered by fractures concentric to the crater. The second group have fewer or no radial fractures visible, the occasional incipient spall fragment, and most have metal smears or traces of the projectile on the crater floor. Both groups show a distinct asymmetry in the $\mathrm{C}$ profile, with a short steep uprange wall and a longer shallow dipping down-range one.

\section{Discussion}

There is a stark contrast in the crater morphology caused by AK-47 projectile impacts into sandstone and limestone targets. For perpendicular impacts, sandstone targets have simple, shallow, bowl-shaped craters, whereas limestone targets exhibit a two part structure of steep sided central pit and shallow dipping outer spall region (dish shaped). This two-part crater morphology is similarly observed during hypervelocity experiments into multiple target lithologies [28-30].

\begin{tabular}{|c|c|c|c|c|}
\hline \multirow{2}{*}{ Angle of Impact } & \multicolumn{2}{|c|}{ AK-47 } & \multicolumn{2}{c|}{ NATO } \\
\cline { 2 - 5 } & $d_{C H C L} / d_{S R S}$ & $D_{C H C L} / D_{S R S}$ & $d_{C H C L} / d_{S R S}$ & $D_{C H C L} / D_{S R S}$ \\
\hline $90^{\circ}$ & 5.85 & 2.37 & 1.18 & 1.25 \\
\hline $45^{\circ}$ & 2.56 & 1.91 & 1.59 & 1.30 \\
\hline
\end{tabular}

Table 3: Ratios of the limestone (CHCL) to sandstone (SRS) crater dimensions show that for all conditions, limestone targets exhibit deeper and wider craters to sandstone counterparts. $d=$ max depth, $D=$ area equivalent diameter.

All limestone targets had deeper and wider crater dimensions than in sandstone targets shot with the same conditions (Table 3). The different response of the two lithologies is due to the target properties, but pinpointing the exact variable is difficult from the experiments presented here. There is a paradoxical relationship between porosity, strength, and crater size. Increased porosity, when viewed independent of stone strength, acts to decrease crater size through the dissipation of energy during pore space collapse [31]. Compressive strength of the target lithology has a similar effect on crater size: the stronger the target material, the smaller the impact craters. However, increasing porosity decreases compressive strength, so while the decreased strength acts to increase crater size, the increased porosity acts to counter this [31,32]. In this study strength reduction appears to have the greatest influence, resulting in larger impact craters in limestone targets ( $20 \%$ porosity) than sandstone targets (11\% porosity) in all experiments. Limestone targets had longer radial fractures with wider apertures than observed in sandstone targets, also possibly linked to the greater porosity in the limestone targets [33]. The considerable differences between the damage caused in the two different rock types emphasises that consideration of target material properties is a key aspect of evaluating and understanding bullet impact damage.

Oblique impacts can be distinguished from perpendicular impacts where stone type and projectile are the same. Perpendicular impacts are deeper and wider than comparable angled impacts, a pattern also observed in hypervelocity experiments with increasing obliquity [30]. This is due to perpendicular impacts transferring more kinetic energy to the target than oblique trajectories. Projectiles with oblique trajectories are more likely to ricochet, retaining kinetic energy that would otherwise be transferred to the target in a perpendicular impact 
[16]. Crater size is also linked to the kinetic energy of the projectile, so with less energy transfer, the maximum stress values experienced in the target may not exceed its strength, resulting in less fracturing and smaller crater dimensions [34-36]. All of the perpendicular impact craters have a broadly symmetrical distribution of damage around the point of impact, with no clear asymmetry in crater profiles. The planform crater shape is roughly circular, but spallation of plate-like clasts from crater edges has modified the crater outlines so that the aspect ratios diverge from 1 (perfectly circular) by average values up to 0.18 . This modification has been observed in other impact experiments into natural stone [29]. $45^{\circ}$ impacts have higher aspect ratios than perpendicular impacts under similar conditions, but in many cases this difference is small, e.g. NATO projectiles into limestone targets (1.19 vs. 1.18) (Table 1$)$. Threshold of aspect ratios for characterising obliquity can be defined fro given targets and projectiles (Table 1). NATO projectile impacts into sandstone targets have the highest aspect ratios, evident from the narrower diameters of the craters in A profiles compared to the $C$ profiles (Figure 2). In hypervelocity experiments involving granite targets, crater elongation does not occur until impact angles fall below $15^{\circ}$, and for loose sediment targets, less than $30^{\circ}$ [16]. However, crater elongation is observed in some conditions at angles of $45^{\circ}$, and cross section profiles in line with the impact trajectory ( $\mathrm{C}$ profiles) show the same steep up range slope and shallow down range slope as oblique hypervelocity experiments [16,37]. Wallis et al. [37] show that subtle asymmetry is present in impacts with even a small degree of obliquity, though these impacts were into aluminium plates, which may not be directly comparable because of their ductile deformation. The Wallis et al [37] study does indicate that any obliquity can cause an asymmetric distribution of damage, suggesting that some regions of stone surrounding the impact will be at risk of faster deterioration than others.

To properly combat future deterioration of impacted stone from weathering, it is important to understand the type of damage and its location. These experiments show that asymmetric cross section profiles, shallower and smaller craters, and higher aspect ratios characterise oblique projectile trajectories. Analogue measurement of profiles using a Barton comb is a simple and cheap way of collecting data in the field. This method can provide measurements of crater depth, diameter, and morphology, without additional processing. The method is however limited to sites and impact damage that are accessible to the researcher. Photogrammetry as an alternative is more versatile in terms of site accessibility and safety: aerial drones can successfully obtain imagery without direct access to a site [18]. Photogrammetry also preserves a digital record of the damage, that can be used to monitor change over time or measure additional variables $[6,38,39]$. On the other hand, this method requires more post-collection processing to turn photographs into usable 3D models, which can be time consuming depending on the number of images and computing power available [40]. This study used between 300 and 400 images to generate 3D models of the target blocks; this number could be reduced and still produce usable models. Gilbert et al. [5] and Campbell et al. [6] created and analysed a good-quality 3D model generated from only 142 images.

Analogue collection methods for crater profiles allows the digital models to be 'ground-truthed' to damage observed in the field. The normalised root mean square difference (RMSN) between the profiles produced by analogue and photogrammetric methods range from $6.0 \%$ to $18.0 \%$. There are several factors to consider when evaluating the difference between analogue and digital profiles. Firstly, the Barton comb has a limited number $(\sim 150)$ of teeth with a set width $(\sim 1 \mathrm{~mm})$, creating a stepped profile that can miss subtle changes in the crater morphology. The digital profile method interpolates between the point cloud data, allowing as many sample points along the profile as desired. This results in a much smoother profile, so even without any other source of difference, profiles from the two methods would not match perfectly. The normalised difference for deeper craters (e.g. those impacted with NATO projectiles) is consistently around $10 \%$. Profiles from both methods are in reasonable agreement with each other, and therefore either method is a viable choice, depending on the specific research aims and conditions of the field site.

The use of non-destructive methods for assessing stone is invaluable for fragile and damaged heritage. For oblique impacts, internal damage, such as fracturing, may be more intense in a downrange direction, as suggested by the shift in the location of peak pressures experienced with increasing obliquity [17]. The use of damage morphology to identify asymmetry and infer a possible downrange direction is a useful first approach to identify regions at risk. Following up with further non-destructive methods, such as surface hardness, ultrapulse velocity, and surface permeability measurements can identify and corroborate damage surrounding impacts $[2,4,5]$. This would identify vulnerable regions at risk of increased capillary rise and salt-driven deterioration, allowing for more comprehensive and specific weathering risk assessments to be made. Such detailed assessments will prove invaluable to the conservation efforts of culturally important sites. 


\section{Conclusions}

In experiments to investigate the surface damage caused by rifle bullets for conditions simulating modern conflicts, impacts excavated craters with diameters from 22 to $74 \mathrm{~mm}$ and depths from 4 to $24 \mathrm{~mm}$. In all conditions, limestone targets had larger crater dimensions that sandstone targets. Limestone targets also exhibit a more complex, two part crater morphology consisting of a central excavation surrounding by a shallow dish shaped spall zone, compared to the simple bowl shape of the sandstone craters. Limestone targets had a higher occurrence of radial fractures extending from the crater to the edge of the block than sandstone targets. Target properties are a major factor in determining the extent and distribution of bullet and shrapnel damage.

Impacts with an incident angle of $45^{\circ}$ produced craters that were shallower and narrower than experiments shot at $90^{\circ}$. Oblique impacts also caused asymmetrical crater profiles, with a steep dipping up range slope and a shallower dipping down range one. Differences between perpendicular and oblique impact damage are quantifiable: for example, crater aspect ratios can distinguish perpendicular from oblique impacts for given target and projectile types. Of the two ammunitions used, the NATO projectiles produced larger and deeper craters than the AK- 47 projectiles, as well as causing the most prominent asymmetry in crater profiles and outlines for oblique impacts.

This characterisation of damage common to contemporary conflicts, with a focus on cultural heritage caught in the crossfire, is important for the conservation of affected sites.

\section{Acknowledgments}

We would like to thank the staff at Cranfield Ordnance Test and Evaluation Centre for their assistance and expertise in conducting the controlled experiments. We thank Ian Thomas for help using Python and fixing bugs in the code. Additional thanks is also expressed to Lieutenant Martin RE for information on military engagement distances and helpful discussions about firearms and ammunition. Further appreciation is expressed to the reviewers for their help in improving the manuscript.

\section{Funding Statement}

This work was funded by the Leverhulme Trust grant number RPG-2017-408.

\section{Data Accessibility}

The datasets supporting this article have been uploaded as part of the Supplementary Material.

\section{Competing Interests}

We have no competing interests.

\section{Authors' Contributions}

All authors provided substantial contribution to the study's conception and design, acquisition of data, and analysis and interpretation of data; drafting and revisions of the article; and are in agreement of approval for the final version of the work submitted and published.

\section{References}

1.

Isakhan B, González Zarandona JA. 2018 Layers of religious and political iconoclasm under the Islamic State: symbolic sectarianism and premonotheistic iconoclasm. Int. J. Herit. Stud. 24, 1-16. (doi:10.1080/13527258.2017.132 5769)

2. Mol L, Gomez-Heras M, Brassey C, Green O, Blenkinsop T. 2017 The benefit of a tough skin: bullet holes, weathering and the preservation of heritage. $R$. Soc. Open Sci. 4, 160335. (doi:10.1098/rsos.160335)

3. Gilbert O, Mol L, Campbell O, Blenkinsop T. 2020 The influence of angle of ballistic impact on stone weathering. In 14th International Congress on the Deterioration and Conservation of Stone, pp. 309-313. Mitteldeutscher Verlag.
4.

Mol L, Gomez-Heras M. 2018 Bullet impacts and built heritage damage 1640-1939. Herit. Sci. 6 , 35. (doi:10.1186/s40494-0180200-7)

5. Gilbert O, Mol L, Campbell O, Blenkinsop T. 2019 Permeability and Surface Hardness Surveying of Stone Damaged by Ballistic Impact. Heritage 2, 1369-1389. (doi:10.3390/heritage2020087)

6. Campbell O, Blenkinsop T, Gilbert O, Mol L. 2021 Surface and Subsurface Damage Caused by Bullet Impacts into Sandstone. Geosciences 11, 395. (doi:10.3390/geosciences1109039 5)

7. Lebedeva MI, Brantley SL. 2017 Weathering and erosion of fractured bedrock systems. Earth Surf. Process. Landforms 42, 2090-2108. (doi:10.1002/ESP.4177)
8. Scherer GW. 2004 Stress from crystallization of salt. Cem. Concr. Res. 34, 1613-1624. (doi:10.1016/J.CEMCONRES.2003. 12.034)

9. Goudie A, Viles HA. 1997 Salt weathering hazard. Wiley.

10. Mol L, Viles HA. 2012 The role of rock surface hardness and internal moisture in tafoni development in sandstone. Earth Surf. Process. Landforms 37, 301-314. (doi:10.1002/ESP.2252)

11. Navarre-Sitchler A, Brantley SL, Rother G. 2015 How Porosity Increases During Incipient Weathering of Crystalline Silicate Rocks. Rev. Mineral. Geochemistry 80, 331-354.

(doi:10.2138/RMG.2015.80.10)

12. Holsapple KA, Schmidt RM. 1987 Point Source Solutions and Coupling Parameters in Cratering Mechanics. J. Geophys. Res. 92, 
6350-6376.

13. Holsapple KA, Schmidt RM. 1982 On the scaling of crater dimensions: 2. Impact processes. J. Geophys. Res. 87, 1849. (doi:10.1029/JB087iB03p01849)

14. Kenkmann $\mathrm{T}$, Wünnemann $\mathrm{K}$ Deutsch A, Poelchau MH, Schäfer F, Thoma K. 2011 Impact cratering in sandstone: The MEMIN pilot study on the effect of pore water. Meteorit. Planet. Sci. 46, 890-902. (doi:10.1111/j.1945-

5100.2011.01200.x)

15. Arakawa M, Shirai K, Kato M. 2000 Shock wave and fracture propagation in water ice by high velocity impact. Geophys. Res. Lett. 27, 305-308.

(doi:10.1029/1999GL010841)

16. Gault DE, Wedekind JA. 1978

Experimental studies of oblique impact. Proc. 9th Lunar Planet. Sci. Conf. 9, 3843-3875.

17. Pierazzo E, Melosh HJ. 2000 Melt Production in Oblique Impacts. Icarus 145, 252-261.

(doi:10.1006/icar.1999.6332)

18. Fernández-Hernandez J, GonzálezAguilera D, Rodríguez-Gonzálvez

P, Mancera-Taboada J. 2015 Image-Based Modelling from Unmanned Aerial Vehicle (UAV) Photogrammetry: An Effective, Low-Cost Tool for Archaeological Applications. Archaeometry 57, 128-145

(doi:10.1111/arcm.12078)

19. Jo YH, Lee CH. 2011 Making Method of Deterioration Map and Evaluation Techniques of Surface and Three-dimensional Deterioration Rate for Stone Cultural Heritage. J. Conserv. Sci. 27, 251-260.

20. Park HD, Shin GH. 2009 Geotechnical and geological properties of Mokattam limestones: Implications for conservation strategies for ancient Egyptian stone monuments. Eng. Geol. 104, 190199.

(doi:10.1016/j.enggeo.2008.10.00 9)

21. Delmonaco G, Margottini C, Spizzichino D, Khrisat B. 2014 Rock slope potential failures in the Siq of Petra (Jordan). Landslide Sci. a Safer Geoenvironment Vol. 3 Target. Landslides , 341-347. (doi:10.1007/978-3-319-049960 52)

22. Franchi $R$, Savelli D, Colosi F, Drapp P, Gabrielli R, Moretti E, Peloso D. 2009 Petra and Beida (Jordan): two adjacent archaeological sites up to an exploitation of geomorphologyrelated topics for a cultural and touristic development Petra e Beida ( Giordania ): due siti archeologici confinanti idonei per una valorizzazione di temi . Mem Descr. Cart. Geol. D'It. LXXXVII, 77-90.

23. MOD-UK. 2018 Army field manual - Warfighting tactics: part 5b; mechanized and light infantry tactics.

24. Fitzsimmons S. 2015 Private Security Companies During the Iraq War-Military performance and the use of deadly force. Taylor \& Francis.

25. Jancosek M, Pajdla T. 2011 Multiview reconstruction preserving weakly-supported surfaces. Proc. IEEE Comput. Soc. Conf. Comput. Vis. Pattern Recognit. , 31213128.

(doi:10.1109/CVPR.2011.5995693 )

26. Moulon P, Monasse P, Marlet R. 2012 Adaptive Structure from Motion with a Contrario Model Estimation. In Asian Conference on Computer Vision, pp. 257-270. (doi:10.1007/978-3-642-374470_20)

27. CloudCompare. 2020 Retrieved from:

http://www.cloudcompare.org/.

28. Polanskey CA, Ahrens TJ. 1990 Impact Spallation ExperimentsFracture Patterns and Spall Velocities. Icarus 87, 140-155.

29. Dufresne A, Poelchau MH, Kenkmann T, Deutsch A, Hoerth T, Schäfer F, Thoma K. 2013 Crater morphology in sandstone targets: The MEMIN impact parameter study. Meteorit. Planet. Sci. 48 50-70. (doi:10.1111/maps.12024)

30. Michikami T, Hagermann A, Morota T, Haruyama J, Hasegawa S. 2017 Oblique impact cratering experiments in brittle targets: Implications for elliptical craters on the Moon. Planet. Space Sci. 135, 27-36.

(doi:10.1016/j.pss.2016.11.004)

31. Poelchau MH, Kenkmann T, Thoma K, Hoerth T, Dufresne A, Schäfer F. 2013 The MEMIN research unit: Scaling impact cratering experiments in porous sandstones. Meteorit. Planet. Sci. 48, 8-22.

(doi:10.1111/maps.12016)

32. Palchik V. 2006 Application of Mohr-Coulomb failure theory to very porous sandy shales. Int. J. Rock Mech. Min. Sci. 43, 11531162.

(doi:10.1016/j.ijrmms.2006.03.00
33. Hatzor YH, Palchik V. 1997 The influence of grain size and porosity on crack initiation stress and critical flaw length in dolomites. Int. J. Rock Mech. Min Sci. 34, 805-816.

(doi:10.1016/S1365 1609(96)00066-6)

34. Rinehart JS. 1968 Intense Destructive Stresses Resultign From Stress Wave Interactions. In Shock Metamorphism of Natural Materials (eds BM French, M Short, Nicholas), pp. 31-42. Baltimore: Mono Book Corp.

35. Zhang ZX, Kou SQ, Jiang LG, Lindqvist PA. 2000 Effects of loading rate on rock fracture: Fracture characteristics and energy partitioning. Int. J. Rock Mech. Min. Sci. 37, 745-762. (doi:10.1016/s13651609(00)00008-3)

36. Holsapple KA. 1993 The Scaling of Impact Processes in Planetary Sciences. Annu. Rev. Earth Planet. Sci. 21, 333-373.

(doi:10.1146/annurev.ea.21.0501 93.002001)

37. Wallis D, Burchell MJ, Cook AC, Solomon CJ, Mcbride N, Burchell † $\mathrm{M} \mathrm{J}$, Cook AC, Solomon CJ, Mcbride N. 2005 Azimuthal impact directions from oblique impact crater morphology. Mon. Not. R. Astron. Soc. 359, 11371149. (doi:10.1111/j.13652966.2005.08978.x)

38. Teza G, Trevisani S, Pesci A. 2019 The role of geoenvironmental sciences in Cultural Heritage preservation: the case of 1000 year old leaning bell tower of Caorle (Venice). J. Cult. Herit. 39, 270-277.

(doi:10.1016/j.culher.2019.03.013 )

39. Kempa M. 1993 Monitoring the Weathering of Stone: Setup and First Results. Int. Arch. Photogramm. Remote Sens. 29, 292.

40. Westoby MJ, Brasington J, Glasser NF, Hambrey MJ, Reynolds JM. 2012 'Structure-from-Motion' photogrammetry: A low-cost, effective tool for geoscience applications. Geomorphology 179, 300-314.

(doi:10.1016/j.geomorph.2012.08. 021) 